\title{
O cotidiano da intersetorialidade e as relações entre as equipes
}

\section{The intersectoriality's daily and the relationships between the teams}

\section{El cotidiano de la intersectorialidad y las relaciones entre los equipos}

\section{Roberta Carvalho Romagnoli*}

Pontifícia Universidade Católica de Minas Gerais - PUC-Minas, Belo Horizonte, Minas Gerais, Brasil

\section{Bruna Coutinho Silva**}

Pontifícia Universidade Católica de Minas Gerais - PUC-Minas, Belo Horizonte, Minas Gerais, Brasil

\begin{abstract}
RESUMO
Este artigo coloca em discussão as relações no cotidiano de trabalho da prática intersetorial do Núcleo Intersetorial Regional Técnico (NIR-T) de uma das regionais de Belo Horizonte, tendo como objetivo discutir conjuntamente os casos de violação social. Esse estudo tem a pesquisa-intervenção como metodologia e as ideias de Deleuze e Guattari como marco teórico. A partir das assembleias, das entrevistas semiestruturadas e das restituições realizadas com as equipes, analisamos as linhas que compõe a prática intersetorial no NIR-T que se fazem na troca entre os setores e os profissionais, nos efeitos dos abalos subjetivos na lida com a vulnerabilidade, nas dificuldades de encaminhamentos e seguimento dos casos, nos limites das próprias políticas públicas e na importância da sustentação do coletivo. Concluímos que a intersetorialidade, mesmo sendo necessária, ainda apresenta muitos desafios.
\end{abstract}

Palavras-chave: políticas públicas, intersetorialidade, pesquisa intervenção, esquizoanálise, intervenção social.

\section{ABSTRACT}

This article discusses the relationships in the daily work of intersectorial practice in the Technical Regional Intersectorial Nucleus (NIR-T), in one of the Belo Horizonte's regional area, and aims to discuss cases of social violation. This study has the intervention research as methodology and the work of Deleuze and Guattari as theoretical framework. Considering the assemblies, the semi-structured interviews and the refunds made with the teams, we analyze the lines that make up the intersectorial practice in the NIR-T that are made in the exchange between the sectors and the professionals, in the effects of the subjective shocks in the handle with the vulnerability, in the difficulties of referrals and follow-up of the cases, in the limits of the public policies and in the importance of the collective. We 
conclude that intersectoriality, although necessary, still presents many challenges.

Keywords: public policies, intersectioriality, intervention research, esquizoanálisis, social intervention.

\begin{abstract}
RESUMEN
Este artículo pone en discusión las relaciones en el cotidiano de trabajo de la práctica intersectorial en el Núcleo Intersectorial Regional Técnico (NIR-T) de una de las regionales de Belo Horizonte, que tiene como objetivo discutir conjuntamente los casos de violación social. Este estudio tiene la investigación-intervención como metodología y las ideas de Deleuze y Guattari como marco teórico. A partir de las asambleas, de las entrevistas semiestructuradas y de las restituciones realizadas con los equipos, analizamos las líneas que componen la práctica intersectorial en el NIR-T que se hacen en el intercambio entre los sectores y los profesionales, en los efectos de los impactos subjetivos en la relación con la vulnerabilidad, en las dificultades de encaminamientos y seguimiento de los casos, en los límites de las propias políticas públicas y en la importancia de la sustentación del colectivo. Concluimos que la intersectorialidad, aun siendo necesaria, todavía presenta muchos desafíos.
\end{abstract}

Palabras-clave: políticas públicas, intersectorialidad, investigación intervención, schizoanalysis, intervención social.

\title{
Belo Horizonte e a prática da intersetorialidade
}

Esse texto trata de tensões e forças vividas nos encontros com as equipes que fazem parte do Núcleo Intersetorial Regional Técnico (NIR-T), de uma regional de Belo Horizonte, dispositivo proposto para sustentar ações coletivas na prática intersetorial, por meio de experimentações de uma produção de conhecimento interventiva e implicada. Pretende, por esse viés, discutir as relações entre os profissionais e a prática da intersetorialidade.

Ao realizar um estudo acerca dos sentidos das ações coletivas no processo de formulação e implementação da Política Nacional da Assistência Social (PNAS), Abade (2016) indica a importância da cidade de Belo Horizonte no processo de construção desta política, que tinha experiências fecundas com os Núcleos de Apoio à Família (NAF) sustentando práticas profissionais de criação, engajamento e construção coletiva. Os NAFs foram implantados dentro de um programa municipal denominado BH Cidadania, no qual já havia fluxos intersetoriais. Fundamentado nos princípios de descentralização, intersetorialidade, territorialidade e participação cidadã, esse programa foi implantado em 2002 em áreas de grande vulnerabilidade social, articulando as ações das secretarias adjuntas de Assistência Social, Segurança Alimentar e Nutricional, Esportes e Direitos de Cidadania, Educação, Saúde, da Fundação Municipal de Cultura e da empresa de informática e informação do município, 
Prodabel, atuando com foco na família e não no indivíduo, isoladamente.

Com essa vocação intersetorial, em 2009, a Prefeitura Municipal de Belo Horizonte instituiu os Núcleos Intersetoriais Regionais (NIRs), vinculados às Secretarias de Administração Regional Municipal, com o intuito de promover a intersetorialidade e a descentralização das ações de inclusão social (Decreto n. 13.660, 2009). Essa portaria institui o NIR Gerencial, composto pelas Gerências Regionais de Políticas Sociais, Educação e Saúde. Na regional estudada, a partir de julho de 2013, o NIR Gerencial instituiu o NIR Técnico, para a discussão dos casos graves de violação de direitos relacionados às políticas setoriais regionais, de modo a agilizar e qualificar a entrega de serviços públicos à população demandante. Composto por profissionais indicados, esse espaço visa ainda fortalecer a interlocução entre as gerências das políticas setoriais regionais, compreendendo e delimitando o papel de cada um no tratamento dos casos apresentados.

A intersetorialidade é uma estratégia essencial para a sustentação das políticas públicas, que ganham novo formato na Constituição Brasileira de 1988 a partir do reconhecimento ao direito às estruturas democráticas e à proteção social para toda a população. Fundamentadas nesse documento, as políticas públicas passam a se responsabilizar pela proposição e fortalecimento de ações (planos, programas e projetos) que possibilitem melhorias nas condições de vida das populações, indicando a necessidade de articulação intersetorial. A intersetorialidade tenta superar a definição setorial das políticas e sua gestão segmentada, uma vez que estas demonstram ineficiência e já não respondem adequadamente aos desafios atuais, produzindo efeitos diretos sobre a atenção aos usuários.

Analisando a intersetorialidade, Monnerat e Souza (2011) apontam para a necessidade de um enfrentamento intersetorial, através da conformação de uma rede de proteção social com a construção de interfaces entre setores e instituições governamentais (e não governamentais), em uma sociedade como a do Brasil, com grandes limites estruturais e desigualdades sociais. Essa rede tem como propósito enfrentar os complexos problemas sociais, que ultrapassam a alçada de um só setor de governo ou área de política pública. A intersetorialidade corresponde à articulação de saberes e experiências para lidar com situações complexas demandando alterações na gestão pública e nas relações de trabalho (Inojosa, 2001). Além dessas mudanças institucionais, a intersetorialidade também deve atuar no cotidiano dos serviços como um dispositivo que permite o encontro com a alteridade, sustentando conflitos e tensões, evitando duplicidade de ações, articulando recursos e ideias. 
Ao estudar as ações intersetoriais a partir da percepção das equipes de saúde de uma unidade de saúde da cidade do Rio de Janeiro, Silva e Tavares (2016) salientam a importância de reconhecer a diferença no outro para se construir um processo comum, o que facilita a construção de redes, colocando em articulação diversos sujeitos, setores e responsabilidades. Dessa maneira, a ampliação dos pactos e das conexões entre as políticas setoriais condiz com uma nova perspectiva de realidade social, em que a complexidade emerge como ponto de partida. Para tanto, as agendas políticas passaram a incluir a intersetorialidade e a interdisciplinaridade como práticas fundamentais em diversas políticas sociais, a exemplo da assistência social, da educação e da saúde.

Nessa direção, o NIR-T, foco deste estudo, concretiza a prática intersetorial. Esse órgão é constituído pelas seguintes equipes: a equipe permanente, que agrega três profissionais que representam uma política cada um, a saber, a educação, a assistência social e a saúde; e as equipes volantes, que contemplam profissionais inseridos nos equipamentos das mesmas políticas, que se organizam conforme os casos discutidos, seja por demandarem a discussão de um caso com o qual trabalham, seja por serem fundamentais na construção de encaminhamentos para os casos discutidos em reunião. Quando uma equipe de profissionais de um equipamento tem dificuldade com determinado caso, ela solicita um horário na agenda do NIR-T, e são chamados todos os equipamentos que trabalham com a família.

Nas reuniões do NIR-T discute-se sobre famílias negligentes com os idosos; adolescentes ameaçados de morte; famílias de pais que fazem uso prejudicial de crack e outras drogas; pessoas com sofrimento mental que não mantêm tratamento adequado e agridem os familiares; pessoas com deficiência sem suporte familiar ou comunitário; pessoas em situação de rua com múltiplas intercorrências de saúde, que não aderem aos acompanhamentos propostos; crianças infrequentes na escola devido a dificuldades de trânsito no território em virtude da violência, dentre outros. Todos os casos estão inseridos em realidades multideterminadas, atravessadas pela pobreza e pela exclusão social, com formas de ser família e de cuidar marcadas pela diferença. Diante de tais casos, sabe-se que nenhuma ação solitária, setorizada, muitas vezes já tentada pelos profissionais, dará conta de construir alguma saída para essas vulnerabilidades.

Constatamos, a partir de reuniões iniciais com a equipe do NIR-T estudado, algumas facilidades e alguns impasses na sustentação efetiva da intersetorialidade. As discussões e as participações dos profissionais envolvem tensões que ora produzem endurecimentos, ora saídas inventivas. Parte dessas tensões é apresentada neste texto. 


\section{Apontamentos metodológicos}

Dada a complexidade da realidade que nos dispusemos a conhecer, este estudo insere-se na linha de pesquisa-intervenção cartográfica, na busca por acompanhar processos presentes no NIR-T em suas ações cotidianas. Ao discutir os modos de fazer pesquisa no campo social, Amador, Lazzarotto e Santos (2015) afirmam que essa modalidade de pesquisa é “... gestada enquanto estratégia de produção de conhecimento combativa ao modelo do projeto moderno de ciência, esse almejando a dicotomização sujeito-objeto, razãorealidade" (p. 231). Nessa direção, pretende romper com tais dicotomias associando pesquisador e população pesquisada em uma produção coletiva de conhecimento, considerando que o campo de investigação é também o espaço concreto de intervenção, e"... sempre se realiza por um mergulho na experiência que agencia sujeito e objeto" (Passos \& Barros, 2012, p. 17), colocando, no mesmo plano, teoria e prática. Partindo do pressuposto de que toda prática de pesquisa é social e produz interferências no campo, a pesquisa-intervenção reconhece que a realidade a ser investigada é composta não só de objetos, mas sobretudo por processos, os quais pretende acompanhar e transformar através da produção de efeitos nas situações cotidianas, localizando-se na interface entre o saber e o fazer.

A pesquisa-intervenção cartográfica, ainda, aborda processos de subjetivação em contraponto às noções de indivíduo e identidade, de modo a reconhecer o sujeito como expressão de forças que 0 atravessam - éticas, políticas, relacionais, estéticas (Ferracini, Lima, Carvalho, Liberman, \& Carvalho, 2014). Tem como intuito não só acompanhar processos, mas provocar mudanças, desestabilizar discursos instituídos e relações que dificultam a invenção. A cartografia apresenta-se como uma postura que sustenta a experimentação do caminho, uma vez que "O cartógrafo não varia de método, mas faz o método variar" (Tedesco, Sade, \& Caliman, 2013, p. 301). A partir dos encontros, dos afetamentos, da análise da implicação, dentre outros, coloca em análise os efeitos das práticas no cotidiano institucional, desconstruindo territórios cristalizados e facilitando a criação de novas práticas nas equipes com as quais produzimos conhecimento. A implicação, por sua vez, rompe com a ideia de neutralidade da ciência moderna, revelando que aquilo que a instituição provoca no pesquisador é sempre efeito de uma produção coletiva, de valores, interesses, expectativas, desejos, crenças que circulam na relação com o campo de pesquisa. Segundo Romagnoli (2014), estar atento a esses efeitos e sustentá-los nos possibilita acessar a instituição através da análise da implicação. A implicação aqui é radicada como princípio, ou seja, é pré-condição da pesquisa o lugar do pesquisador como aquele que também a compõe, aquele 
que se agencia a um coletivo e institui um novo lugar. "Neste sentido, intervir é criar dispositivos de análise coletiva com a problematização permanente dos lugares ocupados por pesquisadores e demais participantes destes coletivos em análise" (Amador et al., 2015, p. 236).

Ao longo da pesquisa, estávamos atravessados pela universidade e pelas agências de fomento com seus prazos e cronogramas, bem como pela postura ético-política de aposta nos coletivos sustentada pelos autores que nos acompanharam no processo de produção do conhecimento. Muitas das exigências e sobrecargas vividas pelas equipes também nos assolavam, reverberando em nossos encontros, nas restituições e em nossos textos. Entendemos que várias instituições e saberes estavam o tempo todo em jogo, que atravessaram o nosso estudo e dos quais éramos intercessores, ora nos endurecendo, ora nos conectando com os profissionais, mas o tempo todo insistindo em uma produção científica que contribua com - cotidiano das políticas públicas cujas demandas chegam cada vez mais à academia.

Usando a metodologia da pesquisa-intervenção, a pesquisa apresenta dois eixos concomitantes de ação para a produção de seus dados, compreendendo a formulação de um campo de análise e um campo de intervenção, que se interpenetram a todo momento. $O$ campo de análise se constitui de levantamento e discussões permanentes da literatura sobre as ideias de Gilles Deleuze, Félix Guattari e Michel Foucault, que sustentam a proposta de pesquisa-intervenção desse estudo, e autores nacionais que trabalham nessa vertente. Efetuamos, ainda, o estudo da intersetorialidade, focando na inclusão social, na violação de direitos e nas famílias em vulnerabilidade social. O campo de intervenção é formado através de um projeto de trabalho coletivo com a equipe dos profissionais que integram o NIR$\mathrm{T}$, acolhendo as demandas e dificuldades locais e envolvendo discussões acerca da dimensão político-institucional (organização do trabalho, relações entre os setores e equipes, relação com as famílias, poder frente aos procedimentos) e da dimensão socioassistencial. Para a produção dos dados utilizamos contatos informais, grupos de discussão, entrevistas semiestruturadas individuais, restituições do material para análise conjunta. Os profissionais que participaram da pesquisa tinham as mais diversas idades (entre 29 e 55 anos) e tempo de inserção nos equipamentos aos quais pertenciam (entre 1 ano e 6 meses e 8 anos), em conformidade com o universo de agentes sociais que trabalham nesses serviços. Eram em sua maioria mulheres, da camada média, envolvidos com a complexidade dos casos e tocados pelos contextos de vulnerabilidade social. Trabalhavam em centros de saúde, abrigos, CRAS, CREAS, CAPS, dentre outros, geralmente com infraestrutura precária e em territórios violentos. 
Os resultados aqui apresentados foram produzidos com a equipe do NIR-T através da restituição, ferramenta essencial nessa modalidade de pesquisa. Sobre a restituição e a participação no processo de pesquisa, Amador et al. (2015, p. 235) destacam que estas “... não constituem uma concessão, mas uma estratégia analítica deste modo de pesquisar-intervir que torna necessário o movimento de composição de um coletivo pesquisador". Estratégia que permite assegurar um pacto de trabalho conjunto por meio da revisão das interpretações efetuadas, possibilitando a expressão das percepções dos participantes e a elaboração coletiva, colocando em análise as instituições e seu cotidiano; no nosso caso, as reuniões e ações articuladas e realizadas pelos profissionais das equipes que participam do NIR-T. A restituição na pesquisa-intervenção pode ser pensada como uma virada nas práticas colonizadoras das pesquisas científicas, colocando o saber produzido por estas a quem 0 possibilitou, até mesmo para discuti-lo (Amador et al., 2015). É nesse entre que a pesquisa-intervenção se coloca para produzir novas forças, tecer um campo de criação de sentidos, conhecimentos e subjetivação relacional, entre pesquisadores e sujeitos-coletivos da pesquisa.

Iniciamos a pesquisa de campo em dezembro de 2015, e a produção de dados até o momento foi feita a partir de cinco observações das reuniões do NIR-T, três restituições, quatro entrevistas com a equipe fixa e seis com a equipe volante, que ocorriam no espaço disponível para o NIR Técnicona regional em questão ou no local em que o profissional atuava. Essas entrevistas foram gravadas e escritas com registro simultâneo, sem transcrição. Acerca da entrevista nessa modalidade de pesquisa, Tedesco, Sade e Calimam (2013) afirmam que esta é um dispositivo que atua, para além da rede de representação, para capturar as modulações da experiência, convocar o plano de forças provocador de rupturas, desvios, para desestabilizar o instituído. Tentamos convocar essas forças em nossos encontros com os membros das equipes.

Começamos a pesquisa com grande apoio e envolvimento da gestão e da equipe fixa do NIR-T e dos participantes das reuniões que seguíamos. Não tivemos dificuldades em nos inserir nas discussões e em fazer as entrevistas. Todavia, ao final, tivemos um fato que, no nosso entender, foi limitador da potencialidade desta pesquisaintervenção: a troca da gestão municipal, que ocorreu no segundo ano de trabalho com a equipe fixa do NIR Técnico. Este foi um complicador do processo, pois tivemos que refazer todos os vínculos e não contamos com o mesmo suporte dos novos atores em cena. As mudanças institucionais reverberaram também na constituição do trabalho coletivo do próprio NIR Técnico, que teve problemas para reiniciar seus encontros e refazer sua equipe fixa em meio às novas contratações e nomeações. Apesar desse atravessamento, os dados 
foram produzidos com a equipe e os profissionais. Além disso, essa pesquisa foi aprovada pelo Comitê de Ética Em Pesquisa (CEP) da PUC Minas, sob registro número CAAE 44396415.9.0000.5137, e atende aos pressupostos éticos das pesquisas com seres humanos.

\section{Rastreando as tensões no cotidiano do NI R-T}

Entendemos que conhecer a prática intersetorial que ocorre no NIR-T é examiná-la em sua complexidade através da imanência existente entre funcionamentos distintos da realidade que ocorrem simultaneamente e de forma processual. Esses movimentos articulam vários elementos dos cotidianos dos serviços, do encontro com as famílias, das distintas apreensões por cada profissão e por cada setor, da vulnerabilidade do caso, dentre outros, e se exercem através de planos que ora formam estratos e segmentos, ora se lançam para fora e inventam estados, se arremessam em devires. Desse modo, baseadas nas ideias de Deleuze e Guattari (1996), entendemos que há uma articulação imanente entre o plano de organização e o plano de consistência que compõem o NIR-T; planos complementares que não existem senão em função um do outro, não possuindo uma lógica excludente. O plano de organização diz respeito ao que está organizado dentro de uma lógica binária, de forma dicotômica e dissociativa, formando as ideias estabelecidas, remetendo ao que está instituído. Esse tipo de funcionamento organiza, estratifica, produz segmentos e dá forma à heterogeneidade da vida, igualando os encaminhamentos, o que se espera da atuação de cada setor, homogeneizando a atuação dos profissionais. Nesse sentido, "Somos segmentarizados por todos os lados e em todas as direções. ... A segmentaridade pertence a todos os estratos que nos compõem" (Deleuze \& Guattari, 1996, p. 83). Por outro lado, o plano de consistência corresponde ao que nos joga para fora desses segmentos, força viva, molecular e invisível, de expansão da vida, possibilidade de agenciar e de construir outros sentidos. É nesse plano que os agenciamentos se engendram e que a diferença é sustentada.

A prática intersetorial não para de oscilar entre esses dois planos que a estratificam, Ihe dão forma e a modelam, mas que também a liberam, permitem escapar das modelizações para criar saídas, inventar encaminhamentos e possibilidades frente à vulnerabilidade dos casos, e muitas vezes também dos técnicos. O plano de organização sustenta o instituído que regula a atuação do NIR-T, com suas diretrizes, com a padronização dos processos de trabalho das políticas setoriais, seus documentos e fluxos de encaminhamentos, ao passo que o plano de consistência diz das suas linhas flexíveis, da interseção fluida e movente, desencadeando devires nos segmentos, 
criando zonas de indeterminação que podem desnaturalizar a visão estratificada dos setores e sustentar uma prática, de fato, transetorial, que articule saberes e disciplinas, desestabilizando as divisões dos campos de saber e dos setores, como assinalam Ornelas e Teixeira (2015). Dessa maneira, o cotidiano da intersetorialidade é produzido na interface entre modelos, ordens e hierarquias que se repetem, e vetores de heterogênese que produzem o novo.

Uma das entrevistadas ressaltou que as reuniões promovem conhecimento e aprendizado. Enfatizando essa necessidade, Azevedo, Pelicioni e Westphal (2012) afirmam que, embora a intersetorialidade possua a capacidade de potencializar as políticas públicas, se depara com a ausência de conhecimento político e técnico de gestores e profissionais para adotar suas ações. Na tentativa de sanar essa carência, o NIR-T torna-se um espaço potencial de formação para os profissionais, já que as situações familiares e comunitárias complexas demonstram os limites da especificidade de cada setor. As violações de direito presentes nos casos discutidos os levam a ampliar a análise do contexto social de cada família, o que pressupõe respostas por vezes inventivas em relação aos protocolos formais. Romagnoli (2007) destaca que a invenção é trabalhada por Gilles Deleuze e Félix Guattari como uma resistência à homogeneização, que apreende a vida ligando-a modelos transcendentes e repetitivos. Os agenciamentos e as conexões que nos tiram desses estratos, deslocam nossas subjetividades através da invenção de outros modos de existência, de novas práticas.

No que tange à formação, as gerências das unidades indicam que os técnicos utilizem o espaço para a discussão de casos limites e essa legitimação favorece com que o NIR-T não seja visto como sobrecarga de trabalho. Esse aprendizado se dá também para os gestores, que geralmente não conhecem as famílias; ao entrar em contato com os casos e os profissionais da ponta, passam a conhecêlas e têm maiores condições de efetuar encaminhamentos. Nesse sentido, a família que vai ser discutida no NIR sai da invisibilidade e vai ter investimento - monitoramento e acompanhamento - dos profissionais.

Contudo, apesar dessa abertura para que linhas flexíveis sejam ativadas, em muitas circunstâncias o plano de organização se fecha e se sedimenta mais, não dando brechas para que linhas de fuga ativas se façam, compondo com forças vitais. Um dos pontos que favorece essa estratificação é o próprio não entendimento do projeto do NIR-T. Uma das componentes da equipe fixa constata que o fato de irem pessoas novas que não entendem bem a proposta dificulta a construção coletiva, uma vez que aquelas pessoas, antes mesmo de escutarem todas as informações do caso, já querem retirar encaminhamentos, pautados em marcos jurídicos. Desse modo, percebemos, com Cavalcanti e Lucena (2016), uma tendência não só 
das equipes, mas dos próprios profissionais de tomar para si a responsabilidade de efetuar ações intersetoriais em detrimento de uma dinâmica em rede. Barros (2009), ao examinar os processos grupais, chama a atenção para o modo-indivíduo de subjetivação, que valoriza o sujeito e a sua dimensão privada, sustentando méritos e fracassos advindos de empreendimentos pessoais, separando essas ações de questões institucionais e sociais e impedindo que linhas de fuga ocorram. Essas linhas duras dominantes, esse plano de organização atravessa a prática intersetorial insistindo na lógica individual em detrimento do coletivo, individualizando questões institucionais que não estão associadas somente aos técnicos, mas também ao plano de forças presentes no NIR-T. Por outro lado, essa postura também se torna problemática quando se vê um esforço de padronização dos casos na busca de soluções rápidas, desconsiderando que cada caso precisa ser avaliado em sua singularidade. Essa ignorância aparece também ligada ao desconhecimento do fluxo das políticas setoriais, em casos que poderiam ser resolvidos na própria política que os encaminha.

Notamos a presença de linhas duras ligadas à necessidade de dar uma solução para o caso, focada não só na produtividade, mas no próprio impacto dos casos na subjetividade dos técnicos. Isso porque "Quanto mais a segmentaridade for dura, mais ela nos tranquiliza" (Deleuze \& Guattari, 1996, p. 109). Não é fácil trabalhar com a vulnerabilidade extrema; as reuniões, em sua maioria, são difíceis, tensas, tratando de casos com graves problemas sociais, econômicos, afetivos, com presença das mais variadas violências e sérias violações de direitos; problemas estes relacionados também às características do território. Uma vulnerabilidade conduzindo à outra, precarizando cada vez mais a vida em sua potência: as famílias que não tiveram acesso à educação não têm também acesso a condições de trabalho favoráveis; vivem em estado de instabilidade; possuem vários problemas de saúde, o que pode aumentar as condições de miséria... Os técnicos usualmente têm a impressão de que os direitos básicos não existem, pois essas situações se repetem com certa constância. Assim, uma delas afirma que há tantas vulnerabilidades na periferia que é como se as condições fossem crônicas, o que leva os profissionais a não terem muita perspectiva de mudança e, desacreditados, assumir em uma postura de lamentação.

Além dessa multideterminação, Siqueira e Lino (2013) apontam para o exercício do poder sobre a vida, denominado por Foucault (1996) de biopoder, que se exerce em processos que refletem sobre a subjetividade, produzindo modos de existência calcados nos discursos científicos. Nessa perspectiva, a garantia dos mínimos sociais, as ações de combate à pobreza, o empoderamento, as medidas protetivas se tornam emblemas da política do "fazer viver". Para tanto, as condutas dos profissionais, já que orientadas por esses 
princípios universais, são também normalizadas, o que potencializa a desconsideração às singularidades. Fuganti (2009) diz que o processo civilizatório cria a lei e a norma como forma de regular as sociabilidades, em nome de um bem maior, da paz, da liberdade, mas nem por isso consegue expurgar dos Estados democráticos a violência; esta se apresenta sutilmente. Até que ponto as práticas reguladoras da vida, através de ações dos profissionais para "ajudar" a família a "reestruturar", "fortalecer suas potencialidades", são investidas daquele poder que exclui o plano da intensidade, do qual emergem saídas, ações, pensamentos ativos, autônomos e criativos das famílias?

Baseando-se em Nietzsche, Fuganti (2009) nos coloca que o modo reativo de existir advém o declínio das intensidades que permitem ao homem constituir modos de vida, ou seja, a conservação da vida emerge como prioridade quando o homem não tem forças de criação o suficiente para se reinventar. Se fizermos uma analogia aos técnicos da nossa pesquisa, podemos pensar como o território no qual se compõem suas ações, marcado por falta de recursos, limite de ações, agravamento de vulnerabilidades, os levam a se distanciarem das forças criativas, que parecem impossíveis. Assim, a reatividade emerge na descrença e impotência na construção de saídas com e pela própria família, pela conservação de modos de vida agravados pelas vulnerabilidades, e não alterados ativa e criativamente.

Nesse cenário, não raro nos deparamos com a descrença dos profissionais, não somente com a intersetorialidade, mas com suas próprias intervenções. Uma das entrevistadas afirma que há técnicos que não veem saídas para alguns casos, pautados no fatalismo e no preconceito, sobretudo em relação aos casos de uso e abuso de álcool e outras drogas, tráfico de drogas e gravidez na adolescência. Sem dúvida, nessas situações, técnicos e famílias se defrontam com a situação de extrema precarização da vida, trazendo abalos subjetivos, como vimos acima, que podem ocasionar até mesmo a saída do cargo. Lidar cotidianamente com situações extremas tem como um dos efeitos a rotatividade de profissionais nas políticas públicas, como foi colocado nas entrevistas. Situações limite convocam o encontro com a alteridade, a exposição ao risco de ter suas próprias referências abaladas e a disposição ou não de encarar o trabalho que lidar com a diferença traz, para além do modoindivíduo. "Contaminar-se pelo outro não é confraternizar-se, mas sim deixar que a aproximação aconteça e que as tensões se apresentem" (Rolnik, 2003, p. 6). Contaminação que se faz pelas linhas flexíveis, podendo-se criar outras composições quando o modo indivíduo se se desfaz e, dependendo das forças que se apropriam das linhas de fuga, produzir linhas ativas, conexões com a alteridade. Pautar ações em nome de algo é ilusório, não toca nas 
singularidades, mas em valores universais, que podem promover dependência, carência, falta, como afirma Fuganti (2009). Olhar para a singularidade como forma de escapar às normalizações próprias e como possiblidade para a invenção constitui uma saída para a descrença e o fatalismo.

Nessa mesma direção temos o risco da psicologização dos casos, guiado pela premissa de que "tudo é saúde mental", que em alguns momentos circula nas discussões do NIR-T. Nessa lógica, os casos que são em si complexos, com determinações das mais variadas ordens, são reduzidos a uma leitura somente subjetiva. Essa lógica convoca ao tratamento dos casos de forma individual, estabelecendo uma composição esvaziada politicamente e torna invisíveis as formas de dominação e exploração que perpassam as questões dos usuários em forte vulnerabilidade social, o que se configura como outra forma de exercício do biopoder. Desse modo, corre-se o risco de que conflitos e assujeitamentos sejam entendidos como patologia, atuando para a despolitização das relações sociais, ao se privatizar os problemas sociais e políticos. Quando isso ocorre, os casos são particularizados em demasia, como se a família fosse a única causadora dos problemas apresentados.

Esse mesmo risco foi indicado por Romagnoli (2006), ao salientar a culpabilização da família amparada em uma lógica dominante de se fazer Psicologia centrada no indivíduo. Essa responsabilização denuncia segmentações finas, estratos moleculares que integram à prática intersetorial, que aparecem nos microfascismos, no julgamento das famílias, no controle sobre como estas deveriam ser, na dificuldade de lidar com a diferença. É preciso prestar atenção a essa miniaturização das linhas duras que impedem linhas de fuga, pois “... os microfascismos têm sua especificidade, eles podem cristalizar num macrofascismo, mas também flutuar por si mesmos sobre a linha flexível, banhando cada minúscula célula" (Deleuze \& Guattari, 1996, p. 110).

Em nossa pesquisa, tanto a equipe fixa quanto os profissionais entrevistados das equipes volantes percebem a importância do NIR-T como espaço de discussão que os fortalece, em escutas acuradas, olhares diferentes que ampliam o conhecimento sobre os casos, as políticas e seus funcionamentos, e também sobre os territórios e suas relações, como colocado pelas entrevistadas. A possibilidade de compartilhar os casos com os colegas da rede faz com que o técnico sinta-se mais seguro e diminua sua solidão em intervenções que não vinham se mostrando eficazes para dar conta da situação apresentada. Nessa direção, Silva e Tavares (2016), ao analisar ações intersetoriais na atenção primária no Rio de Janeiro, apontam que um dos desafios da intersetorialidade é a manutenção do trabalho em equipe, pois "Esse novo fazer demanda mudanças de valores da cultura para um agir coletivo" (p. 195). Farias, Sá, 
Figueiredo e Menezes Filho (2016) destacam, em estudo acerca da intersetorialidade no Programa Saúde na Escola (PSE), em um município de Pernambuco, que a superação dos problemas de saúde requer a intersetorialidade para a construção de ações integradas, uma vez que esta é mais efetiva e dispõe de relações horizontais, de corresponsabilidade. Azevedo, Pelicioni e Westphal (2012) defendem a interdisciplinaridade, a valorização do território e as redes sociais que facilitam processos participativos na busca de dinâmicas coletivas. Dias, Parente, Vasconcelos e Dias (2014) destacam a necessidade de ultrapassagem de modelos reducionistas na micropolítica do cotidiano para o avanço da intersetorialidade. Todos esses autores atestam a importância dos grupos e dos coletivos para a sustentação da prática intersetorial.

A proposta no NIR-T é de cada setor se associar a partir de sua especificidade, para traçar estratégias conjuntas e mais eficazes. Uma de nossas entrevistadas diz que o esperado seria as pessoas que compõem cada encontro do NIR-T viessem já capazes de assumir que possuem um saber e abertas para se apropriar de outros, uma vez que a construção coletiva consiste na conexão entre esses saberes em propostas para os casos discutidos. Entendemos que o fazer coletivo pode gerar efeitos atuando para a produção de outros modos de subjetivação. Para Escóssia e Kastrup (2005), o coletivo não seria resultado de uma soma de pessoas, mas de processos moleculares e intensivos que emergem no plano de organização, fazendo com que as linhas duras que o compõem se tornem mais fluidas e conectivas. Diluindo o estrato, o intensivo aflora e cria um campo coletivo composto por forças diversas que se agenciam e promovem deslocamentos subjetivos. "Agenciar-se com alguém... não é substituí-lo, imitá-lo ou identificar-se com ele: é criar algo que não está nem em você nem no outro, mas entre os dois, neste espaçotempo comum, impessoal e partilhável que todo agenciamento coletivo revela" (Escóssia \& Kastrup, 2005, p. 303). Esse plano coletivo e relacional faz com que alguns técnicos percebam essa potência para resolutividade de casos complexos, por ser uma rede de saberes e práticas distintas que se reúnem para uma construção coletiva de estratégias de intervenção, caso a caso, e avaliam esse espaço já como um grande avanço na política municipal. Coletivo este que ora é conquistado, ora se dilui em formas estabelecidas de cuidar de cada equipamento, na leitura de cada especificidade e formação, na ênfase de cada setor, como examina Romagnoli (2017) ao abordar a intersetorialidade como um rizoma, composto por linhas duras e linhas de fuga.

Retornando às linhas duras, a questão mais unânime no que se refere à dificuldade da prática da intersetorialidade diz respeito à falta de comunicação e ao seguimento dos casos. Os técnicos têm uma reclamação recorrente de que, após o encaminhamento dado em 
cada reunião, eles não têm mais retorno do que se passou, apontando para uma falta de organização e dificultando uma avaliação a longo prazo. Serafino e Luz (2015) encontram essa mesma realidade no trabalho com a população adulta em situação de rua, no Rio de Janeiro, denunciando a ausência de retorno dos casos nos encaminhamento sem todos os níveis de complexidade entre as políticas sociais. A questão da continuidade das ações intersetoriais também aparece no estudo de Silva e Tavares (2016): "Os depoimentos declaravam que a integralidade das ações carecia de continuidade e comprometimento junto à comunidade para trabalhar sua autonomia e conscientização" (p. 199). Gonçalves, Silva, Pitangui, Silva e Santana (2015) afirmam que os técnicos de referência no atendimento de crianças e adolescentes vítimas de violência, em uma unidade de saúde em Pernambuco, relatam descontinuidade das ações intersetoriais, expressas pela ausência do seguimento dos casos, e de contrarreferências, pela falta de comunicação entre as políticas setoriais envolvidas e por ações isoladas de profissionais.

A dificuldade de acompanhar os encaminhamentos e saber, de fato, se foram ou não efetivos, apareceu diretamente em uma das reuniões do NIR-T colocada por um dos técnicos da equipe volante. $\mathrm{Na}$ ocasião, a equipe de pesquisa indagou acerca dos impedimentos para que isso acontecesse, emergindo a dificuldade de diálogo no cotidiano da rede e a atuação solitária no retorno aos equipamentos. Entendemos que a institucionalização do NIR-Tse faz nas contradições institucionais que se expressam nos serviços, comportando tensões que não se encontram nos documentos e nem nas propostas oficiais das políticas públicas. Como nos lembra Monceau (2013), a pesquisa intervenção, denominada pelo autor de trabalho sócio clínico, atua como um dispositivo que produz efeitos sobre os grupos, as pessoas e as organizações, interferindo em seu cotidiano, desvelando contradições e trazendo forças de renovação e invenção mais autônomas. Assim, os grupos presentes na reunião decidiram fazer um grupo de e-mail com os técnicos referenciados dos casos, também para evitar novas discussões do mesmo caso, uma vez que o NIR-T é um espaço de discussão e não de retorno, com grandes demandas e com pouca possiblidade de rediscutir os encaminhamentos. Podemos pensar que a tensão "discussão do caso" versus "retorno" ainda é uma questão a ser enfrentado no próprio NIR-T, emergindo como um ponto que denuncia suas contradições. Uma das entrevistadas nos colocou que, a despeito da organização de tal grupo de e-mails, a comunicação para seguimento dos casos não se efetivou como prática contínua. Ponderou-se que muitos técnicos não leem os e-mails, ou justificam o não retorno ao demandante do encaminhamento dos casos pela falta de tempo, devido aos inúmeros casos atendidos em seu equipamento, o que dificulta a eficácia dessa 
troca de informações. Cavalcanti e Lucena (2016) indicam que um dos obstáculos para a materialização da intersetorialidade refere-se à sobrecarga de obrigações dos profissionais em seus setores, o que contribuiu para a manutenção do conservadorismo das ações, e, em nosso estudo, para a busca imediata de soluções, muitas vezes sem discussão dos casos. Raichelis (2010) ao examinar a inserção dos profissionais no SUAS denuncia a precarização das condições de trabalho nesse campo, através de processos de alienação, restrição de sua autonomia técnica e intensificação de tarefas, vinculando-se a essas condições insatisfatórias, baixos salários. Silva e Tavares (2016) ressaltam a necessidade de se repensar os processos de trabalho do cotidiano no que diz respeito às metas, que são muitas e ocupam grande parte do tempo de trabalho. De novo, o plano de organização impedindo que fissuras se façam e ganhem intensidade nos agenciamentos.

Uma das entrevistadas afirma que, embora os profissionais tenham boas ideias, esbarram nos limites das políticas públicas que possuem falhas no sentido protetivo. Existem muitas dificuldades de relacionamento com as políticas públicas estatais. No NIR-T aparecem vários casos de violência domiciliar, negligência, abusos e violações de direitos, que demandam a intervenção de órgãos de defesa de direitos das crianças, adolescentes e idosos. Nessas situações, é frequente 0 não comprometimento dos profissionais que integram esses órgãos. Não só o NIR-T se faz a partir de tensionamentos, mas as próprias políticas favorecem a coexistência de práticas que afirmam a construção de modos de gestão e cuidado aliados a processos singulares que insistem na produção de autonomia, mas também práticas que sustentam relações de poder que gerenciam a vida. Assim, o Estado lança mão de estratégias neoliberais de forma a garantir o funcionamento capitalista, administrando a desigualdade social e naturalizando a miséria e a vulnerabilidade, mantendo linhas duras que compõem planos de organização estáticos e rígidos.

Alguns profissionais apontam dificuldades também com a gestão no nível municipal, tais como a troca de gestão na mudança dos prefeitos, a falta de recursos, o corte de gastos constantes nas políticas de assistência social, educação e saúde. A gestão também não prioriza em manter os profissionais, através de concursos, capacitações, condições de trabalho. Uma das entrevistadas atesta que o trabalho do NIR-T tem potencialidades, mas pode ser melhor com envolvimento dos gerentes. Silva e Tavares (2016) indicam a necessidade do apoio da gestão para ampliar essas ações integradoras e no envolvimento da população usuária da política; a equipe pode se sentir impotente e limitada em relação às ações intersetoriais no cotidiano, uma vez que dependentes de condução por parte da gestão. Em seu trabalho sócio clínico, Monceau (2013) destaca que no encontro da gestão com o trabalho social produzem- 
se embates nos quais o trabalho social é desvitalizado por esse confronto, frente aos quais os trabalhadores devem encontrar novas saídas. Aparecem forças potentes e difíceis de reconhecer, que se manifestam e são imprevisíveis. Em uma das reuniões, uma assistente social de um centro de saúde e uma conselheira tutelar trouxeram ao NIR-T a sugestão de escreverem um documento solicitando ao secretário regional outros equipamentos no bairro do caso em discussão, uma vez que lá só tem centros de saúde e escolas estaduais. Esse documento foi feito e encaminhado.

Os profissionais notam a ausência de outras políticas públicas participando do NIR-T, que seriam fundamentais, dentre elas a política de habitação e a política de segurança pública. O estudo de Ornelas e Teixeira (2015) sobre o Projeto Teias, que associa a Fundação Oswaldo Cruz, o Governo do Estado e a Secretaria Municipal de Saúde do Rio de Janeiro, também identificou no diálogo existente com a saúde, a educação e a assistência social a falta de articulação com setores importantes, como a segurança pública e o Programa de Aceleração do Crescimento (PAC). I sso demonstra que nem todos os setores chave para a realização de ações congruentes com as demandas e vulnerabilidades do território se inserem na rede de articulação intersetorial. Em estudo de Farias et al. (2016) também foi notada a ausência de integração de outras políticas setoriais, salvo em situações pontuais.

Entre pontos potencializadores e pontos que se estratificam, linhas são traçadas na prática intersetorial do NIR-T, como campo de análise e de intervenção. Linhas ora duras, que insistem na reprodução e podem se manter por microfascismos, ora flexíveis, que permitem captar os movimentos coletivos desse campo, assim como linhas de fuga, que podem fazer eclodir uma prática através de agenciamentos entre vários setores e agentes. Movimentos que se fizeram presentes em nossa pesquisa.

\section{Considerações Finais}

A prática intersetorial, embora conste no texto das políticas públicas, ainda apresenta grandes desafios nas relações entre as equipes, entre os profissionais de uma mesma equipe e na relação com os territórios e usuários. Em nosso estudo percebemos algumas dificuldades que atravessam o dia-a-dia da intersetorialidade, a saber: impacto dos casos na subjetividade dos técnicos; falta de comunicação e seguimento dos casos; sensação de sobrecarga por parte dos profissionais; limite das próprias políticas públicas; dificuldades também com a gestão a nível municipal; ausência de outras políticas públicas. Pontos que circulam imanentemente com as facilidades que o trabalho intersetorial proporciona: a partilha de 
casos; o fortalecimento das ações dos profissionais; a formação dos técnicos, dentre outros.

A possibilidade de ações coletivas nos permite apostar na força do intensivo em respostas transetoriais para tanta vulnerabilidade. Para tentar evitar o risco de os serviços na prática continuarem centralizados e distantes das necessidades reais da população brasileira, é preciso operar por agenciamentos, que viabilizam uma rede rizomática e conectam os mais variados elementos da realidade e dos setores, não se reportando a uma única combinação. Acreditamos que o NIR-T, para além das linhas duras que compõem seu plano de organização, pode ser experimentado também como um espaço potente que se cria nas tensões existentes entre modos ressentidos e frustrados, gerando posturas ativas e inventivas.

\section{Referências}

Abade, F. L. (2016). Os sentidos das ações coletivas no PAIF (Tese de Doutorado). Pontifícia Universidade Católica de Minas Gerais, Belo Horizonte, Brasil.

Amador, F. S., Lazzarotto, G. D. R., \& Santos, N. I. S. (2015). Pesquisar-agir, pesquisar-intervir, pesquisar-interferir. Revista Polis e Psique, 5(2), 228-248. Recuperado de http://seer.ufrgs.br/index.php/PolisePsique/article/view/58180/ pdf_26

Azevedo, E., Pelicioni, M. C. F., \& Westphal, M. F. (2012). Práticas intersetoriais nas políticas públicas de promoção de saúde. Physis: Revista de Saúde Coletiva, 22(4), 1333-1356. doi: 10.1590/S0103-73312012000400005

Barros, R. D. B. (2009). Grupo: a afirmação de um simulacro. Porto Alegre: Sulina, UFRGS.

Cavalcanti, P. B., \& Lucena, C. M. F. (2016). O uso da promoção da saúde e a intersetorialidade: tentativas históricas de integrar as políticas de saúde e educação. Polêmica, 16(1), 24-41. doi: 10.12957/polemica.2016.21332

Decreto n. 13.660, de 03 de agosto de 2009. (2009). Institui os Núcleos Intersetoriais Regionais - NIR, e dá outras providências. Belo Horizonte: Diário Oficial do Município.

Deleuze, G., \& Guattari, F. (1996). Micropolítica e segmentaridade. In G. Deleuze \& F. Guattari, Mil Platôs: capitalismo e esquizofrenia (Vol. 3, pp. 83-115). Rio de Janeiro: Editora 34.

Dias, M. S. A., Parente, J. R. F., Vasconcelos, M. I. O., \& Dias, F. A. C. (2014). Intersetorialidade e Estratégia Saúde da Família: tudo ou quase nada a ver? Ciência \& Saúde Coletiva, 19(11), 4371-4382. doi: 10.1590/1413-812320141911.11442014 
Escóssia, L., \& Kastrup, V. (2005). O conceito de coletivo como superação da dicotomia indivíduos sociedade. Psicologia em Estudo, 10(2), 295-304. doi:10.1590/S141373722005000200017

Farias, I. C. V., Sá, R. M. P. F., Figueiredo, N., \& Menezes Filho, A. (2016). Análise da Intersetorialidade no Programa Saúde na Escola. Revista Brasileira de Educação Médica, 40(2), 261-267. doi: 10.1590/1981-52712015v40n2e02642014

Ferracini, R., Lima, E. M. F. A., Carvalho, S. R., Liberman, F., \& Carvalho, Y. M. (2014). Uma experiência de cartografia territorial do corpo em arte. Urdimento, 1(22), 219-232. doi: $10.5965 / 1414573101222014219$

Foucault, M. (1996). Microfísica do poder (12a ed.). Rio de Janeiro: Edições Graal.

Fuganti, L. (2009). Biopolítica e produção de saúde: um outro humanismo? Interface - Comunicação, Saúde, Educação, 13(Supl. 1), 667-679. doi:10.1590/S141432832009000500017

Gonçalves, C. F. G., Silva, L. M. P., Pitangui, A. C. R., Silva, C. C., \& Santana, M. V. (2015). Atuação em rede no atendimento ao adolescente vítima de violência: desafios e possibilidades. Texto \& Contexto - Enfermagem, 24(4), 976-983. doi:10.1590/01040707201500004580014

Inojosa, R. M. (2001). Sinergia em políticas e serviços públicos: desenvolvimento social com intersetorialidade. Cadernos FUNDAP, (22), 102-110. Recuperado de https://www. pucsp. br/prosaude/downloads/bibliografia/sinergia _politicas_servicos_publicos.pdf

Monceau, G. (2013). Effets d'une pratique clinique de recherche. In: R. C. Kohn (Coord.), Pour une démarche clinique engagée ( $p p$. 91-104). Paris: L'Harmattan.

Monnerat, G. L., \& Souza, R. G. (2011). Da Seguridade Social à intersetorialidade: reflexões sobre a integração das políticas sociais no Brasil. Revista Katálysis, 14(1), 41-49. doi: 10.1590/S1414-49802011000100005

Ornelas, A. L., \& Teixeira, M. G. C. (2015). Intersetorialidade ou diálogos setoriais? Reflexões a partir da experiência do Projeto Teias-Escola Manguinhos, Rio de Janeiro. Saúde em Debate, 39(106), 659-670. doi: 10.1590/0103-110420151060003008

Passos, E., \& Barros, R. (2012). Pistas do método da cartografia: pesquisa-intervenção e produção de subjetividade. Porto Alegre: Sulina.

Raichelis, R. (2010). Intervenção profissional do assistente social e as condições de trabalho no SUAS. Serviço Social e Sociedade, (104), 750-772. doi: 10.1590/S0101-66282010000400010 
Rolnik, S. (2003). Alteridade a céu aberto: o laboratório poéticopolítico de Maurício Dias \& Walter Riedweg. In Posiblemente hablemos de lomismo, catálogo da exposição da obra de Mauricio Dias e Walter Riedweg (pp. 6-41). Barcelona: MacBa, Museu d'Art Contemporani de Barcelona.

Romagnoli, R. C. (2007). A resistência como invenção: por uma clínica menor. Vivência, 1(32), 97-107.

Romagnoli, R. C. (2006). Famílias na rede de saúde mental: um breve estudo esquizoanalítico. Psicologia em Estudo, 11(2), 305-314.

Romagnoli, R. C. (2014). O conceito de implicação e a pesquisaintervenção institucionalista. Psicologia e Sociedade, 26(1), 4452. doi: 10.1590/S0102-71822014000100006

Romagnoli, R. C. (2017). Transversalizando as políticas públicas: quando a intersetorialidade torna-se rizomática. Psicologia em Estudo, 22(3), 421-432. doi: 10.4025/psicolestud.v22i3.35843

Serafino, I., \& Luz, Lila C. X. (2015). Políticas para a população adulta em situação de rua: questões para debate. Revista Katálysis, 18(1), 74-85. doi:10.1590/141449802015000100008

Silva, D. A. J., \& Tavares, M. F. L. (2016). Ação intersetorial: potencialidades e dificuldades do trabalho em equipes da Estratégia Saúde da Família na cidade do Rio de Janeiro. Saúde em Debate, 40(111), 193-205. doi:10.1590/01031104201611115

Siqueira, K. O. M., \& Lino, M. V. (2013). Assistência Social e Biopoder: produzindo "vulnerabilidades", prevenindo "riscos" e normalizando as formas de viver. Mnemosine, 9(2), 35-53.

Tedesco, S. H., Sade, C. \& Caliman, L. V. (2013). A entrevista na pesquisa cartográfica: a experiência do dizer. Fractal, Revista Psicologia, 25(2), 299-322. doi: 10.1590/S198402922013000200006

\section{Endereço para correspondência \\ Roberta Carvalho Romagnoli}

Rua Terra Nova, 101, ap. 401, Sion, CEP 30315-470, Belo Horizonte - MG, Brasil Endereço eletrônico: robertaroma1@gmail.com

\section{Bruna Coutinho Silva}

Rua São Leopoldo, 86, Santa Cruz, CEP 31130-710, Belo Horizonte - MG, Brasil Endereço eletrônico: bcoutinho.psi@gmail.com

Recebido em: 03/01/2019

Reformulado em: 08/03/2019

Aceito em: 20/03/2019 


\section{Notas}

* Doutorado em Psicologia Clínica pela Pontifícia Universidade Católica de São Paulo (2003) e pós-doutorado em Análise Institucional pela Université Cergy-Pontoise, França (2011). Atualmente é Professor Adjunto III da Pontifícia Universidade Católica de Minas Gerais, na graduação e na pós-graduação em Psicologia.

** Graduação em Psicologia pela Pontifícia Universidade Católica de Minas Gerais (2018). Cursando pós-graduação em Filosofia Contemporânea pela PUC Minas. Bolsista de Apoio Técnico pela mesma universidade.

Financiamento: CNPq e FAPEMIG.

Este artigo de revista Estudos e Pesquisas em Psicologia é licenciado sob uma Licença Creative Commons Atribuição-Não Comercial 3.0 Não Adaptada. 